in November 1954 by Butterworths. There will be two volumes : vol. 1 will cover medical and physiological applications, and vol. 2 physical sciences and industrial applications.

In addition to the formal papers, there were films illustrating radioisotope techniques used in hospitals and laboratories. By the courtesy of Lord
Cherwell, the Clarendon Laboratory was available for a well-laid-out exhibition covering instruments, laboratory techniques and a representative range of manufacturers' equipment (representing five different countries) of interest to radioisotope users. This was a centre of activity throughout the week.

J. E. Johnston

\title{
CHEMISTRY IN RELATION TO THE DEVELOPMENT OF THE NERVOUS SYSTEM
}

$\mathrm{T}$ HE Mental Health Research Fund organized the First International Neurochemical Symposium at Magdalen College, Oxford, during July 13-17. The Symposium was planned as part of a series, and the field selected for the first meeting was "Chemistry in Relation to the Development of the Nervous System". The organizing committee consisted of J. Elkes (Birmingham), L. Flexner (Philadelphia), J. Folch-Pí (Boston), G. W. Harris (London), S. S. Kety (Washington), D. Richter (Cardiff) and $\mathrm{H}$. Wrelsch (New York).

The Symposium was attended by approximately seventy scientific workers, forty being from abroadfrom Belgium, Canada, Denmark, Germany, Italy, Norway, Sweden, the United States and U.S.S.R. It was arranged in morning and afternoon sessions, and on two days there was also an evening session. Each session started with one or two reviews, followed by communications on recent research; there was always a lively and full discussion, and this was recorded. The transcription of the Symposium will be published in the near future by the Academic Press, New York.

The first morning session, under the chairmanship of Sir Geoffrey Vickers, was characterized by two features : the regrettable absence of Dr. R. Lorente de Nó (New York), and the view expressed by the two anatomists in discussing some aspects of the early development of the nervous system (Prof. J. D. Boyd, of Cambridge) and of the vascular patterns of the nervous system (Dr. Horne Craigie, of Toronto) that chemical inductors are required for explaining the morphological development of the nervous system. Prof. Boyd emphasized the importance of the tissue and the spaces underlying the ectoderm in the development of the dorsal plate and the differentiation of the neural tissue, illustrating his points with a wealth of material from sheep embryos. Dr. Horne Craigie showed the wide range of vascular patterns presented in the development of a variety of species, and posed the question of the extent to which the pattern is determined by underlying changes.

The afternoon session, with Dr. R. W. Gerard (Chicago) in the chair, opened with a review of experimental neuroembryology in the chick by Dr. V. Hamburger (St. Louis), and an account of the functional development of the nervous system in the dogfish by Dr. H. P. Whiting (Bristol). Dr. Hamburger took up the theme of the morning session and reported on the dramatic changes in the growth of spinal and sympathetic ganglia produced by the influence of transplanted limb buds and tumour tissue. Dr. Whiting presented experimental evidence for dividing the developmental steps into the classical divisions of myogenic, neurogenic and reflexogenic, and in general supported the Coghill thesis of segregation of reflexes. There followed a communication by Dr. J. L. Malcolm (London) on his investigations into the appearance of inhibition and facilitation in the developing spinal cord of kittens. He showed that, during the first two post-natal days, an impulse sent in through the dorsal lumbar roots leads only to a single spike in the corresponding ventral root, but that later, with the appearance of after-discharge in the ventral root, facilitation and inhibition can be demonstrated. The session ended with a communication from Dr. D. Hill (London), in which he emphasized the important practical aspects of cerebral maturation as marked by the milestones which can be demonstrated by the electroencephalo. gram rhythms.

The second day started, under the chairmanship of Dr. S. S. Kety, with a detailed review by Dr. Folch-Pi of the composition of the whole brain of mice during post-natal maturation, with particular reference to phospholipids, a review which was based to a great extent on the extensive work done in his own laboratory. This review was followed by Dr. H. Klüver's (Chicago) careful fluorospectrographic analysis of porphyrins in the central nervous system. They are not present in the central nervous system of reptiles, amphibians and fishes, and are found in warm-blooded animals only after birth-for example, in rats at the age of 20-25 days, a time which is associated with a number of functional advents. Porphyrins occur first in the ventral roots and last in the cerebrum; Dr. Klüver thinks their presence is related to the developing oligodendroglia. These photodynamic substances may be affected by the amount of light known to be transmitted through the skull in some species, and the interesting question arises as to the extent to which light may, by these means, affect nervous system activity and also, perhaps, the sexual cycle. Dr. P. Diezel (Heidelberg) presented histochemical evidence of the distribution of iron throughout the brain substance, and pointed out the considerable amounts which appear in the glial cells during development, while Dr. G. Brante (Eskilstuna) reported on the presence of polysaccharide substances in the nervous tissue of developing mice. Dr. A. F. W. Hughes (Cambridge) described his technique for the refined densitometry measurements of ribonucleic acid in the developing chick embryo, and was able to demonstrate its appearance and distribution in the ventral horn cells and its relationship to the Nissl substance. The morning session finished with an account by Dr. 
D. R. Davies and Dr. L. C. Thomas (Salisbury) on their infra-red spectrophotographic method for measuring quantitatively the myelin in the developing nervous tissue. They stressed the point that this method might be applicable to a number of problems associated with myelination.

The afternoon session, under the chairmanship of Prof. H. A. Krebs, started with a carefully worked out review by Dr. D. Richter (Cardiff) on the chemistry, particularly enzymes and substances such as acetylcholine, glutamic acid and glycine, in the developing brain. The material, which was often given in clear tables, will be of great use for subsequent reference when published in the Symposium. Dr. S. S. Kety (Washington) reported on his work, with the nitrous oxide method, on the oxygen consumption of the brain in the human, and made the observation that at birth nearly 80 per cent of the oxygen consumption is accounted for by brain metabolism, that between ten and twenty years the percentage is more than 50, and that later it falls to about 25 per cent. Then Dr. H. MeIlwain (London) gave an account of his experiments, together with Dr. P. Greengard, on the oxygen consumption of tissue slices of the cerebral cortex of rats and guinea pigs of varying ages. They showed how the oxygen consumption can be raised to an increasing extent with age by means of electrical potential gradients in the Warburg chamber, the presumption being that such potentials stimulate the cortical tissue to activity comparable to that found in vivo. The role of non-nervous tissue was assessed by comparable measurements on gliomas. Dr. R. W. Sperry (Pasadena) followed with an account of the effects of transplanted skin in tadpoles and its effect on subsequent innervation, and, most intriguing, the re-organization of the connexions in the central nervous system.

An evening session was held on the second day, and for this the chair was taken by Dr. L. B. Flexner (Philadelphia). The subject of the geometrical properties of the constituents of the nervous system was ably outlined by Dr. A. Pope (Boston), who discussed, among other problems, the quantitative aspects of inter- and intra-cellular material. The remainder of the evening was devoted to histochemistry of a most refined nature. Dr. O. H. Lowry (St. Louis) gave a fascinating account of his technique for weighing and the subsequent chemical analysis of individual neurones, a feat which won the universal admiration of the audience, as did his apparently casual method of presentation. No less interesting was Dr. H. Hydén's (Gothenburg) description of his methods of measuring the light and X-ray absorption of single nerve cells, from which the lipid protein and ribonucleic acid content can be assessed. How many of his audience envied him a machine which automatically types the results!

On the morning of the third day, with Sir Rudolph Peters in the chair, Dr. H. Waelsch (New York) opened by reviewing the differences in the rate of replacement of substances in the developing and adult brain; the results were obtained with the use of the isotope technique. He showed that in the first week of the developing brain of rats 40 per cent of the fatty acids is replaced, whereas there is a much smaller turnover in the adult rat. With the exception of glutamine, he has obtained no evidence that amino-acids are synthesized into the adult brain however, from experiments on tissue cells there is some indication that essential amino-acids may be synthesized in immature brain tissue; but the mechanism of the uptake of these amino-acids is not clear. $\mathrm{He}$ stressed the point that in the embryonic or immature brain the blood-brain barrier appears to be absent; but so far the number of substances examined is not sufficiently large to allow this general conclusion. He was followed by Dr. H. E. Himwich (Galesburg), who gave an account of the relative rates of uptake of glutamine by adult and young rat brain, concluding that the rate of uptake in the younger age group is relatively greater. The lipid content of the brain was discussed by Dr. W. M. Sperry (New York) as well as by Dr. R. M. C. Dawson (Oxford). Dr. Sperry's results were obtained from human material from 4 to 40 days post natal, and he emphasized the need to correlate the increased lipid content over this period not only with the rate of medullation but also with the changes in the water and nervous tissue space. Dr. Dawson presented evidence of the rate of deposition of phospholipids in the young mouse brain, and presented evidence for a phospholipid metabolic cycle. Prof. A. V. Palladin (Kiev) read a paper on the metabolism of nucleic acids in the developing brain. Investigations in his Institute have shown that the protein content increases during the development of the brain, that despite the concomitant decrease in nucleic acid content the metabolism increases, that the grey matter of the cerebrum has a higher content of nucleic acids, of ribonuclease, and of desoxyribonuclease than the white matter, and that the cerebellum is rich in nucleic acids, especially desoxyribonucleic acid. He stressed the important role of these substances during the morphological and functional development of the brain. Prof. G. E. Vladimirov (Leningrad) in his report dealt with the role of the blood-brain barrier, and presented data collected during the turnover of such substances as adenosine triphosphoric acid, creatine phosphate, etc., using labelled phosphorus. By estimating the iron in blood, in brain tissue free from blood, and brain tissue containing blood, the quantity of blood contaminating the brain tissue was assessed, and errors in estimating the true intracellular content of phosphorus avoided. By such experiments the specific activity of intracellular inorganic phosphates is found to be equal to that of adenosine triphosphate.

The afternoon, with Dr. W. Feldberg (London) in the chair, saw the presentation of a great deal of evidence for the change in enzyme content in relationship to age. Dr. L. B. Flexner (Philadephia) opened with a survey of the growth of various enzyme systems in the guinea pig cortex, and he was able to relate their appearance with that of the corticel electroencephalogram, the presence of strychnine spikes, and the development of the earliest movements evoked by stimulation of the cortex. $\mathrm{He}_{\Theta}$ presented evidence for a large increase in the chloride and sodium space at a time (forty-sixth day) when recognizable electroencephalogram pattcrns and strychnine spikes are observed. In the ensuing discussion some scepticism was expressed about the interpretation of the difference between sodium and chloride spaces in terms of Hodgkin's theory of a sodium pump mechanism as a basis for neuronal activity. Both Dr. H. E. Himwich (Galesburg) and Prof. J. Elkes and Dr. A. Todrick (Birmingham) presented figures for the rate of appearance of cholinesterases in the various parts of rat and rabbit brain, while Dr. M. A. Gerebtzoff (Liège) presented histochemical studies of the distribution of cholin 
esterases in the rat spinal cord. None of these findings could yet be directly tied to actual functional investigations. The session concluded with a paper by Dr. W. K. Jordan (Little Rock) on the increase of adenosine triphosphate in the rat cortex and cerebellum during the first forty days after birth. The increase was correlated with the appearance of spontaneous action potentials which began as short bursts of activity. In the cortex the periods between the bursts greatly decreased between the tenth and twentieth day; in the cerebellum at a somewhat later period.

Prof. L. S. Penrose took the chair on the morning of July 16, when Dr. Salome G. Waelsch (New York) outlined some of the genetic factors involved in the development of the central nervous system, in which she gave a stimulating account of her own work on mutations of mouse central nervous system. Of particular interest were her experiments in the modification of genes by antigen-antibody reactions, and her preliminary findings indicate an extremely interesting future for this method of investigation. The second review, by Prof. E. Klenk (Cologne), was on the possible role of cerebrosides in the pathology of the nervous system. Two short papers presenting original material by Dr. R. W. Gerard and Dr. L. Abood (Chicago) and by Sir Rudolph Peters (Oxford) completed the morning. Drs. Gerard and Abood have investigated the chemistry of the nervous system of the $D b a$ strain of mice which between the twentyeighth and thirty-sixth day post-natal is extremely susceptible to auditory stimulii. Dr. Gerard suggested that the low adenosine triphosphatase activity found at this period could account for the apparent hyperexcitability of the nervous system, if the membrane potential is related to the creatine phosphate content. Sir Rudolph Peters spoke about his interesting experiments on convulsions produced by fluorocitrate and its probable mode of action as a competitive inhibitor of aconitase; he discussed the probable reasons for the inability to reverse the competitor by calcium.

In the afternoon session, under the chairmanship of Prof. R. Gjessing (Oslo), the chemical changes accompanying well-defined mental defects were considered. Prof. L. S. Penrose (London) spoke about the genetic factors involved in the transmission of a number of known metabolic deficiencies, and Dr. $H$. Bicket (Birmingham) described the control of phenylketonuria by a suitable diet in several cases which he had studied in collaboration with Dr. Gerrard and Dr. Boscott. Finally, Dr. H. Weil-Malherbe (Runwell) presented data on the relationship of blood adrenaline to a large series of mental diseases.

The evening session was devoted to films. Dr. Hughes showed, by means of some extremely good time-lapse photography, the growth processes of chicken neurones, growing in suitable culture media; a fine sequence showing mitosis of a neurone was included in this film. Dr. Feldberg showed a film made by him and Dr. S. Sherwood of the method used for introducing drugs beyond the blood-brain barrier directly into the lateral ventricles of the cat. The action of a series of drugs producing changes of awareness such as stupor, catatonia and anæsthesia, as well as motor effects such as scratching, itching, paralysis and convulsions, were clearly shown with this film. He stressed the fact that from this region of the brain we can easily produce, by the action of small amounts of drugs, conditions which have much in common with mental diseases in man-for example, epilepsy and schizophrenia. Dr. H. Bickel's (Birmingham) short film of the three cases of phenylketonuria, which had been discussed earlier in the day, showed dramatically the recovery which is possible with a diet low in phenylalanine. His film emphasized the difficulties inherent in the control of such cases and the need of hospitalization. Finally, a sound film from Prof. D. Bovet's laboratory in Rome demonstrated skilfully the use of the electroencephalogram in the investigation of drug effect on the central nervous system.

In the closing session on the morning of July 17, with Dr. H. Klüver in the chair, the high standard of the previous days and the intense interest which had been shown in the discussions at all previous sessions were maintained. Prof. G. W. Harris (London) gave a brief but extremely lucid account of the early endocrine-nervous system relationships, with particular reference to the growth of control by the hypothalamus on the pituitary, and indirectly on other endocrine organs. Dr. D. Nachmansohn (New York) gave a short account of his conception of the basic biochemistry associated with the conduction of the nerve impulse, indicating the points in the energy cycles involved at which drug action might be expected to take place. The remaining papers related, in varying degree, to clinical problems, emphasizing their important place beside the highly theoretical discussions which had taken place on the previous days. Dr. J. T. Eayrs (Birmingham) described the relationship of a nerve cell and its background substance in cases of hypothyroidism, with particular reference to the probable inability of dendrites to grow when the background substance is deficient. Dr. M. Reiss (Bristol) presented evidence of the relationship between steroid hormone deficiencies and the incidence of mental states, and Dr. S. P. Hicks (Boston) showed the selective action of $a$ number of agents, such as X-rays, on different parts of the developing nervous system. He gave some interesting data on the selective action of drugs, such as acetylpyridine, on certain parts of the nervous system. Finally, Dr. J. Elkes (Birmingham) spoke of the work done in collaboration with Dr. Eayrs and Dr. Todrick on the effect of inhibition of cholinesterase in the central nervous system during the period of development, pointing out that 80 per cent inhibition of this enzyme has little interference with subsequent development and function.

The closing remarks, presented by Prof. $R$. Gjessing (Oslo), admirably expressed the opinion and the feelings of all those present. $\mathrm{He}$ expressed their gratitude to the organizers for bringing such a comprehensive group of workers together, and felt that, if the symposium had only emphasized the many gaps in our knowledge, that alone would have made it worth while. He expressed the admiration of the meeting for the extreme thoroughness of the organization, which attended not only to their serious discussions but provided a most enjoyable evening in Magdalen College Hall with entertainment from the Oxford Madrigal Society and others. In fact, much of the success of the meeting was no doubt due to the many opportunities for informal discussion in the delightful surroundings of Magdalen College.

$$
\begin{aligned}
& \text { W. Feldierg } \\
& \text { J. L. Malcolm }
\end{aligned}
$$

National Institute for Medical Research, Mill Hill, London, N.W.7. 